\title{
Influence of Cowpea (Vigna unguiculata) Peptides on Insulin Resistance
}

\author{
Barnes $\mathrm{MJ}^{1}$, Uruakpa $\mathrm{FO}^{2 *}$ and Udenigwe $\mathrm{CC}^{3}$ \\ ${ }^{1}$ Pennington Biomedical Research Center, Nutrition \& Neural Signaling Lab, Baton Rouge, LA, USA \\ ${ }^{2}$ Missouri State University, Department of Biomedical Sciences, Springfield, MO, Missouri \\ ${ }^{3}$ Dalhousie University, Department of Environmental Sciences, Truro, NS, Canada
}

Received: February 18, 2015; Accepted: April 28, 2015; Published: May 05, 2015

*Corresponding author: Florence Uruakpa, Department of Biomedical Sciences, Missouri State University, Springfield, MO 65897, Tel: +417 836

5603; Fax: +417 836 5588; E-mail: ojiugou@yahoo.com

\begin{abstract}
Biomolecules from cowpea (Vigna unguiculata) can be beneficial in the reduction of hyperglycemia and strengthening the antioxidant status of individuals with diabetes. L6 rat skeletal muscles were exposed to various doses of cowpea peptides $(0.1,1,10$ and 100 ng) for 20 hours or insulin $(100 \mathrm{nM})$ for 30 minutes. Proteins were isolated from the treated cells and analyzed by Western blot for the phosphorylation of Akt (a form of protein kinase B; PKB). Study findings show that the cowpea peptides can induce Akt phosphorylation in the cell culture. This indicates that administering the cowpea peptides to the skeletal muscle cells can activate the insulin signaling cascade. It is probable that cowpea peptides can mimic the actions of insulin by activating the same signaling cascade.
\end{abstract}

Keywords: Insulin signaling; Cowpea peptides; Anti-diabetic agents; health-promoting bioactives

\section{Introduction}

Insulin is a hormone, produced by the pancreas, which regulates carbohydrate and fat metabolism in the body. A major target tissue for insulin's action is the skeletal muscle. Glucose uptake in the skeletal muscle occurs in response to insulin binding to its receptors, stimulating the insulin signaling cascade and allowing translocation of the glucose transporter (i.e. GLUT4) to the plasma membrane. Mitigation of its function in skeletal muscle results in the development of insulin resistance, a condition that is associated with diabetes. Strong evidence indicates that oxidative stress is involved in the development of insulin resistance [1]. According to Martins et al. [2], oxidative stress can occur from elevated glucose and free fatty acids which increase the production of Reactive Oxygen Species (ROS). ROS such as hydroperoxyl $\left(\mathrm{HOO}^{\circ}\right)$, hydroxyl $\left(\mathrm{HO}^{\circ}\right)$ and superoxide anion $\left(\mathrm{O}_{2}{ }^{--}\right)$radicals are physiological metabolites that result from respiration in aerobic organisms. These ROS are very unstable, and react rapidly with other substances, e.g., membrane lipids and proteins, and DNA. Oxidative stress is produced by an imbalance between oxidizing species and natural antioxidants in the body, and has been associated with cell apoptosis, aging, and chronic disease conditions such as cancer, Parkinson's, Alzheimer's, and cardiovascular diseases [3].

Furthermore, ROS has been proposed to be the underlying cause for the development of insulin resistance. Current treatments for insulin resistance are associated with significant side effects. Therefore, there is a need for the development of safer and effective alternative therapies. In this regard, plants have been found to be a rich source of medicinal compounds with beneficial effects.

In 2009, diabetes accounted for approximately 70,000 deaths, making this disease the seventh leading cause of death in the United States [4]. This disease and all of its medical complications (e.g. heart disease, kidney disease, digestive disease, etc.) presents an enormous economic impact on healthcare. In 2007, the direct and indirect cost for medical care for individuals with diabetes was $\$ 174$ billion [5]. Due to these medical complications, new efforts towards developing strategies for prevention and treatment of diabetes are highly needed. One such strategy is the use of medicinal compounds from plants such as cowpea (Vigna unguiculata).

Legumes are widely cultivated and constitute an excellent source of protein (20-30\% protein). Cowpea (Vigna unguiculata), also called black-eye pea/bean, is a protein-rich and droughtresistant legume. It is widely grown in Africa, Latin America, Southeast Asia and southern United States. A cowpea protein isolate was reported to have a similar molecular weight and amino acid sequence as bovine insulin, and was thought to be a potential functional food with anti-diabetic and antioxidant activities [6]. In another report, cowpea peptides ( $\alpha$ - and $\beta$-antifungal proteins) were shown to exhibit antifungal and antiviral properties [7].

In recent years, food proteins have gained increasing value due to rapidly expanding knowledge about physiologically active peptides. For instance, peptides from various dietary protein sources have been shown [8] to have positive effects on health by functioning as antihypertensive, antioxidant, anticarcinogenic and antimicrobial agents, among others. These properties have led to their being labeled as functional or biologically-active (i.e., 
bioactive) peptides. For example, a recent in vitro study on the effects of cowpea peptides on lipid metabolism reported that cowpea peptides can act as antioxidants and inhibit the enzyme needed for biosynthesis of cholesterol, and its micellar solubility [9]. The objective of this study was to investigate the anti-diabetic characteristics of cowpea peptides in a rat skeletal muscle cell culture; considering the potential of cowpea peptides in health promotion.

\section{Materials and Methods}

Rat L6 skeletal muscle cells obtained from American Type Culture Collection (Manassas, VA) was used. Cells were grown in Dulbecco's MEM (DMEM) (US Biological, Swampscott, MA) supplemented with 10\% Fetal Bovine Serum (FBS) and $50 \mu \mathrm{g} /$ $\mathrm{ml}$ penicillin/streptomycin in a humidified chamber with $5 \%$ carbon dioxide at $37^{\circ} \mathrm{C}$. Prior to beginning studies, L6 myoblasts was sub-cultured onto 6 well plates and grown to $80-90 \%$ confluence and differentiated into fused myotubes for 5 days by switching to media that contained $2 \%$ FBS. All cells were used within five passages. L6 myotubes (rat skeletal muscles) were exposed to various doses of the cowpea peptides $(0.1,1,10$ and $100 \mathrm{ng}$ ) for 20 hours or insulin (100 nM) for 30 minutes. Samples were collected, protein isolated and Western blot analysis was performed to observe the phosphorylation of Akt, a signaling molecule in the insulin signaling pathway required to induce glucose transport.

\section{Insulin signaling cascade}

Cells were exposed to various doses of the cowpea peptides for 20 hours. Insulin $(100 \mathrm{nM})$ was used as the control and applied to cells for 30 minutes. At the end of the incubation period, proteins were isolated from the cells followed by sonication in lysis buffer and centrifugation at $15,000 \times \mathrm{g}$. Following electrophoresis, protein was transferred to PVDF membranes (Pierce, Rockford IL) and blocked for one hour (room temperature) in 5\% dried milk. Following several washes, membranes were incubated overnight with phospho-Akt (pAkt) antibody. Beta-actin was used as the loading control. The film was incubated with a secondary antibody (Cell Signaling, Danvers MA) and washed. Membranes were developed and exposed to radiograph film.

\section{Results and Discussions}

Recent research has been on the association/link between food and health, with emphasis on the physiological functions of some food components against certain diseases. For instance, peptides derived from food proteins are known to exhibit a wide range of health-promoting bioactivities, including their roles as physiological modulators of metabolic processes [8]. Diabetes mellitus is an important metabolic disease characterized by high blood sugar level, and many treatment and management strategies for this disease have been based on the utilization of plants and plant parts [10].

In this study, cowpea-derived peptides were evaluated for the prospect of regulating glucose homeostasis based on Akt phosphorylation (activation) in skeletal cell culture. The images in figure 1 are Western blot analysis showing the phosphorylation

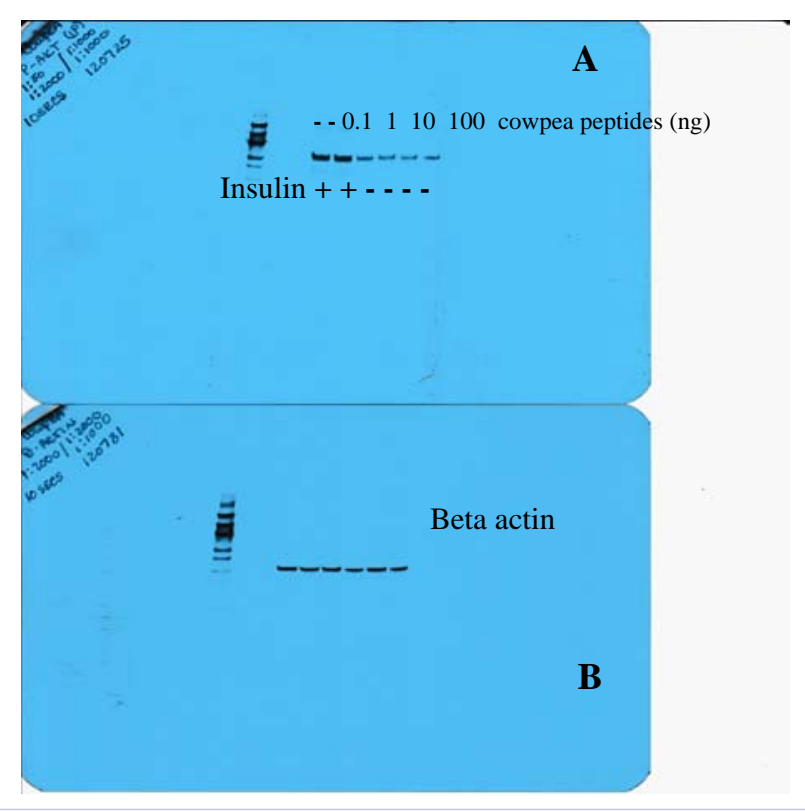

Figure 1: Phosphorylation of Akt by the cowpea peptides and insulin. In A: the first two lanes are insulin; and the remaining lanes are different doses of the cowpea peptides.

In B: beta-actin was used as the loading control

of Akt. Data from this study demonstrate that administering the cowpea peptides to L6 myotubes resulted in the phosphorylation of Akt. An important note is that phospho-Akt is a signaling molecule in the insulin signaling pathway that is required to induce cellular glucose transport. It is probable that the cowpea peptides can mimic the actions of insulin by activating the same signaling cascade.

This study provides evidence to support the prospective utilization of cowpea peptides as anti-diabetic agents. The findings demonstrate that the cowpea peptides can function in glucose metabolism via phosphorylation of Akt; which can potentially lead to the reduction in blood sugar levels. Akt (a form of protein kinase $\mathrm{B}$; $\mathrm{PKB}$ ) is a serine/threonine-specific protein kinase that plays a key role in multiple cellular processes such as glucose metabolism, apoptosis, cell proliferation, transcription and cell migration. Studies have suggested that cAMP-elevating agents could activate PKB through protein kinase A (PKA) in the presence of insulin [11].

A study on Vigna unguiculata corroborates the findings of this study regarding the insulin-like property of the cowpea peptides. Based on the reports, amino acid sequence of a protein isolated from $V$. unguiculata was found to be similar to the sequence of bovine insulin [6,12]. Moreover, an isolated insulin-like plant protein was shown to decrease the concentration of blood glucose in normal and diabetic mice [12]. Bioactive peptide sequences may be encrypted within the amino acid sequence of the larger protein. These peptides usually consist of 3-20 amino acids and are released from the original protein after degradation $[13,8]$. Thus, bioactive peptides derived from the cowpea proteins can 
offer potential benefits as physiological modulators of glucose metabolism.

\section{Conclusion}

Cowpea proteins could play vital role in managing chronic diseases such as diabetes. Findings of this study indicate that the cowpea peptides can mimic the actions of insulin by inducing Akt phosphorylation in cultured skeletal cells. This study is ongoing to determine if these same observations are evident in an experimental animal model of diabetes.

\section{References}

1. Bashan N, Kovsan J, Kachko I, Ovadia H, Rudich A. Positive and negative regulation of insulin signaling by reactive oxygen and nitrogen species. Physiol Rev. 2009; 89(1): 27-71. doi: 10.1152/physrev.00014.2008.

2. Martins AR, Nachbar RT, Gorjao R, Vinolo MA, Festuccia WT, Lambertucci RH, et al. Mechanisms underlying skeletal muscle insulin resistance Induced by fatty acids: importance of the mitochondrial function. Lipids Health Dis. 2012; 11: 30. doi: 10.1186/1476-511X11-30.

3. Giasson BI, Ischiropoulos H, Lee VY, Trojanowski JQ. The relationship between oxidative/nitrosative stress and pathological inclusions in Alzheimer's and Parkinson's diseases. Free Radic Biol Med. 2002; 32(12): 1264-75.

4. Kochanek KD, Xu J, Murphy SL, Minino AM, Kung HC. Deaths: Final Data for 2009. Natl Vital Stat Rep. 2011; 60(3): 1-116.

5. Center for Disease Control and Prevention. National Diabetes Fact Sheet: national estimates and general information on diabetes and prediabetes in the United States. 2011.
6. Venancio TM, Oliveira AE, Silva LB, Machado OL, Fernandes KV, Xavier Filho J. A protein with amino acid sequence homology to bovine insulin is present in the legume Vigna unguiculata (cowpea). Braz J Med Biol Res. 2003; 36(9): 1167-73.

7. Ye XY, Wang HX, Ng TB. Structurally dissimilar proteins with antiviral and antifungal potency from cowpea (Vigna ungiculata) seeds. Life Science. 2000; 67: 3199-207.

8. Udenigwe CC, Aluko RE. Food protein-derived bioactive peptides: production, processing, and potential health benefits. J Food Sci. 2012; 77(1): R11-24. doi: 10.1111/j.1750-3841.2011.02455.x.

9. Marques MR, Soares Freitas RA, Corrêa Carlos AC, Siguemoto ÉS, Fontanari GG1, Arêas JA. Peptides from cowpea present antioxidant activity inhibit cholesterol synthesis and its solubilization into micelles. Food Chem. 2015; 168: 288-93. doi: 10.1016/j.foodchem.2014.07.049.

10. Korczowski MM. Dietary control of diabetes: reality or myth? South Med J. 1985; 78: 979-86.

11. Stuenaes JT, Bolling A, Ingvaldsen A, Rommundstad C, Sudar E, Lin FC, et al. Beta-adrenoceptor stimulation potentiates insulinstimulated PKB phosphorylation in rat cardiomyocytes via cAMP and PKA. Br J Pharmacol. 2010; 160(1): 116-29. doi: 10.1111/j.14765381.2010.00677.x.

12.Xavier Filho J, Oliveira EAA, da Silva LB, Azevedo CR, Venâncio TM, Machado OLT, et al. Plant insulin or glucokinin: A conflicting issue. Braz J. Plant Physiol. 2003; 15: 67-78. doi: 10.1590/S167704202003000200002 .

13. Möller NP, Scholz-Ahrens KE, Roos N, Schrezenmeir J. Bioactive peptides and protein from foods: indication for health effects. Eur J Nutr. 2008; 47(4): 171-82. doi: 10.1007/s00394-008-0710-2. 